\title{
Pregnant Woman with Positive Sars CoV2 and Newborn Immunity
}

\section{ISSN: 2640-9666}

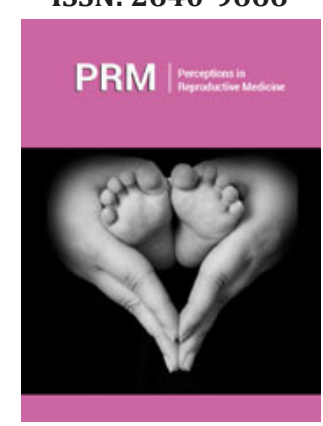

*Corresponding author: Medical Faculty, Indonesia

Submission: 眥 February 12, 2021

Published: 愖 February 25, 2021

Volume 4 - Issue 3

How to cite this article: Muhammad Anas, Gina Noor Djalilah. Pregnant Woman with Positive Sars CoV2 and Newborn Immunity. Perceptions in Reproductive Medicine. 4(3). PRM. 000590. 2021.

DOI: 10.31031/PRM.2021.04.000590

Copyright@ Muhammad Anas, This article is distributed under the terms of the Creative Commons Attribution 4.0 International License, which permits unrestricted use and redistribution provided that the original author and source are credited.
Muhammad Anas* and Gina Noor Djalilah

Medical Faculty, Indonesia

\section{Case Report}

The patient was a 35-year-old pregnant (G3P2A1) woman at 31 weeks of gestation who had a fever and cough for six days, relatively normal clinical laboratory results, and tested positive for SARS-CoV-2 on June $26^{\text {th }}, 2020$. After self-isolation for 14 days, and she got symptomatic treatment and supplementation daily RT-PCR for SARS-CoV-2 evaluation tested, and the results were negative. After that, the patient-controlled every two weeks until 38-39weeks of gestation. The baby was labor by normal delivery with the consideration that the mother had negative results evaluation for SARS-CoV-2. The baby was born on August $23^{\text {rd }}$, 2020, with Apgar, score 7, and 8 with oxygen saturation up in range 96-98, the normal value of the vital sign. The Newborn was transferred to the mother room and got early initiation of breastfeeding. The Newborn had an evaluation laboratory with a result of haemoglobin levels $16.9 \mathrm{~g} / \mathrm{dl}$, leucocytes $9.2 \times 109 \mathrm{~L}^{-1}$, platelets $171 \mathrm{x} 103$, Erythrocyte sedimentation rate 57.4, random blood sugar 63 , and C-reactive protein $18.8 \mathrm{mg} / \mathrm{L}$. The newborn on the second day of ages got a rapid test for SARS-CoV-2 with IgG positive, Ig M negative, level of quantitative 95.03. The baby in stable condition and regularly home after three days in the hospital due to an increase in CRP levels.

\section{Discussion}

The mother had a fever and cough for about six days on 31 weeks of gestation. Mild or moderate flu-like symptoms were the majority of pregnant women with COVID-19 disease. Some women may have fever, cough, and shortness of breath. Older women who are immunosuppressed or have chronic diseases such as diabetes, cancer, and chronic lung disease will have pneumonia, and significant hypoxia is mostly. However, there can be a group of asymptomatic women or those with minor symptoms carrying the virus; the incidence of such women is unknown [1]. The transmission of SARS-CoV-2 is still controversial from the infected pregnant woman to the fetus. Viremia is seen in only 1\% of COVID-19 cases, suggesting that placental and fetal seeding might be quite rare [2].

The newborn was transferred to the mother room and got early initiation of breastfeeding. The optimal delivery method of infected mothers is still controversial [3]. In pregnant women with SARS-CoV-2 infection, there is not an indication for routine cesarean delivery except for obstetrical reasons, but cesarean delivery was preferred mostly to reduce the length of hospital stay, minimize the chance of cross-infection, reducing maternal physical exertion during delivery, and ensuring the safety of other people at the clinic [4]. The newborn got early initiation of breastfeeding. The mother and infant should be enabled to remain together while rooming-in throughout the day and night and to practice skin-to-skin contact, including kangaroo mother care, especially immediately after birth and during the establishment of breastfeeding, whether they or their infants have suspected or confirmed COVID-19 [5]. The newborn got breastfeeding from her mother. WHO recommends that mothers with suspected or confirmed COVID-19 should be encouraged to initiate or continue to breastfeed. Mothers should be counseled that the benefits of breastfeeding substantially outweigh the potential risks for transmission [5]. Breastmilk is generally considered safe against viral infections because of its protective contents such as immunoglobulins and other bioactive compounds. Breast milk may contain anti- SARSCoV-2 antibodies in infected mothers, but there is no 
data yet on this issue. On the other hand, various case reports have concluded that breast milk does not contain the virus RNA (CDC) [6].

The baby had complete blood count laboratory results with hemoglobin levels $16.9 \mathrm{~g} / \mathrm{dl}$, leucocytes $9.2 \mathrm{x} 109 \mathrm{~L}^{-1}$, platelets $171 \times 103$, lymphocyte $36.6 \%$, monocyte $6 \%$, granulocyte $57.4 \%$, erythrocyte sedimentation rate 57.4, random blood sugar 63 and C-reactive protein $18.8 \mathrm{mg} / \mathrm{L}$. Whether suspected or confirmed, asymptomatic infants should have a complete blood count, C-Reactive Protein (CRP), and Real Time-PCR for SARS-CoV-2. It is preferable to take the samples at least from 2 sites, including the upper respiratory tract, lower respiratory tract, or blood. Feces may be obtained and kept for further analysis (Diagnosis and management of new coronavirus infection) [7].

The baby had laboratory result evaluation on the second day of ages with a rapid test for SARS-CoV-2 with IgG positive, Ig M negative, level of quantitative 95.03. IgG is passively transferred across the placenta from mother to fetus beginning at the end of the second trimester and reaches high levels at the time of birth [8,9]. Maternal IgM does not cross the placental barrier intact; therefore, positive IgM in early infants is potential evidence of intrauterine vertical transmission [10]. The duration of passive immunity from maternal $\operatorname{IgG}$ is still unclear. However, IgG is transferred passively from mother to fetus through the placenta [10]. In a study of mothers with SARS, the placentas of 2 women who were convalescing from SARS-CoV infection in the third trimester of pregnancy had abnormal weights and pathology [11,12].

\section{References}

1. Alzamora MC, Paredes T, Caceres D, Webb CM, Valdez LM, et al. (2020) Severe COVID-19 during pregnancy and possible vertical transmission. Am J Perinatol 37(8): 861-865.

2. Wang W, Xu Y, Gao R, Lu R, Han K, et al. (2020) Detection of SARS-CoV-2 in different types of clinical specimens. Jama 323(18): 1843-1844.

3. Ludvigsson JF (2020) Systematic review of COVID-19 in children shows milder cases and a better prognosis than adults. Acta Paediatr 109(6): 1088-1095.

4. Qi H, Luo X, Zheng Y, Zhang H, Li J, et al. (2020) Safe delivery for pregnancies affected by COVID-19. BJOG 127(8): 927-929.

5. (2020) World Health Organization. Breastfeeding and Covid 19 Interim Guidance. WHO, Switzerland.

6. (2020) Centers for Disease Control. Coronavirus Disease (COVID-19) and Breastfeeding. Centers for Disease Control.

7. Ovali F (2020) SARS-CoV-2 infection and the newborn. Front Pediatr p.

8. Kohler PF, Farr RS (1966) Elevation of cord over maternal IgG immunoglobulin: Evidence for an active placental IgG transport. Nature 210(5040): 1070-1071.

9. Zeng H, Xu C, Fan J, Tang Y, Deng Q, et al. (2020) Antibodies in infants born to mothers with COVID-19 pneumonia. Jama 323(18): 1848-1899.

10. Kimberlin DW, Stagno S (2020) Can SARS-CoV-2 infection be acquired in utero?: More definitive evidence is needed. Jama 323(18): 1788-1789.

11. Ng WF, Wong SF, Lam A, Mak YF, Yao H, et al. (2006) The placentas of patients with severe acute respiratory syndrome: A pathophysiological evaluation. Pathology 38(3): 210-218.

12. Gao J, Li W, Hu X, Wei Y, Wu J, et al. (2020) Disappearance of SARS-CoV-2 antibodies in infants born to women with COVID-19, Wuhan, China. Emerg Infect Dis 26(10): 2491-2494. 